\title{
Nanobody-based quantification of GTP-bound RHO conformation reveals RHOA and RHOC activation independent from their total expression in breast cancer.
}

Laura Keller ${ }^{1,2, \$}$;Claudine Tardy ${ }^{1,+}$; Laetitia Ligat ${ }^{3}$; Julia Gilhodes, ${ }^{4}$; Thomas Filleron ${ }^{4}$; Nicolas Bery ${ }^{1}$;Philippe Rochaix ${ }^{4}$; Alexis Aquilina ${ }^{5}$; Sara Bdioui ${ }^{5}$; Thomas Roux ${ }^{5}$; Eric Trinquet $^{5}$; Gilles Favre ${ }^{1,2, *}$; Aurélien Olichon ${ }^{1,6, *}$

${ }^{1}$ Centre de Recherche en Cancérologie de Toulouse (CRCT), INSERM, Université de Toulouse, CNRS, UPS, Toulouse, France

${ }^{2}$ Laboratoire de Biologie Médicale Oncologique, Institut Claudius Regaud, IUCT-Oncopôle, Toulouse, France;

${ }^{3}$ Le Pôle Technologique du Centre de Recherches en Cancérologie de Toulouse, plateau de protéomique, Toulouse, France;

${ }^{4}$ Service de Biostatistiques, Institut Claudius Regaud, IUCT-Oncopôle, Toulouse, France.

${ }^{5}$ Cisbio Bioassays, Codolet, France

${ }^{6}$ INSERM, UMR 1188 Diabète athérothrombose Réunion Océan Indien (DéTROI), Université de La Réunion, Saint-Denis de La Réunion, France

*To whom correspondence may be addressed. E-mail: aurelien.olichon@inserm.fr and gilles.favre@inserm.fr

$\$$ These authors contributed equally to this work

Supplemental Information table of contents.

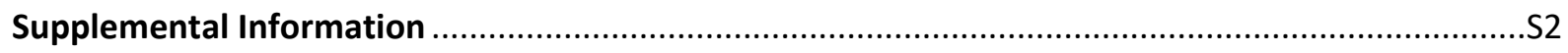

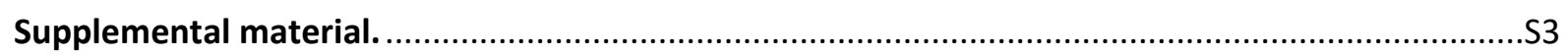

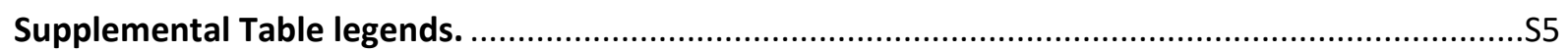

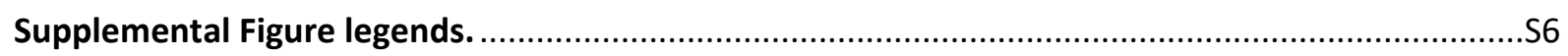

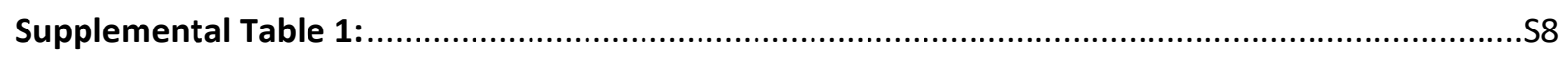

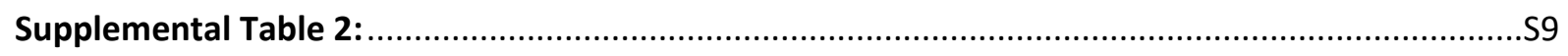

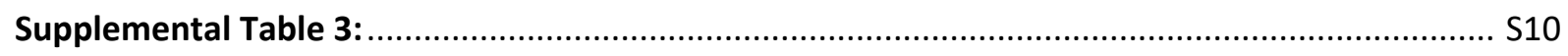

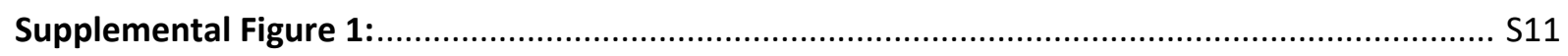

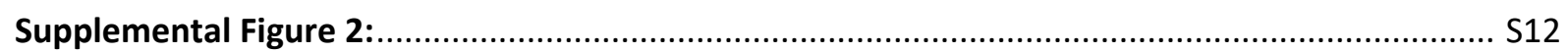

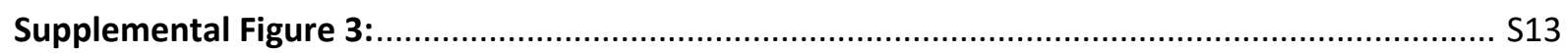

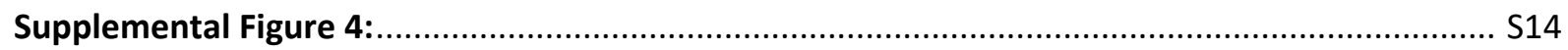

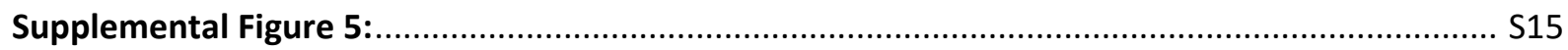

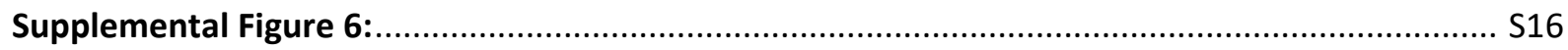

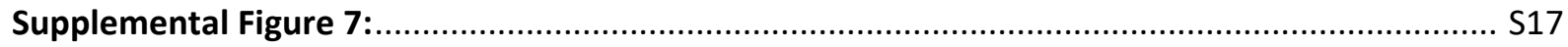

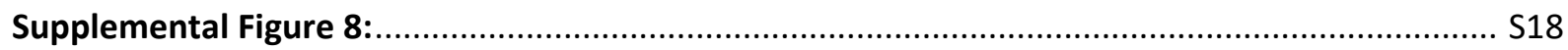




\section{Supplemental Information}

Validation of the RH12-6His-myc-6His expressed in E.coli B121(de3). The purified RH12-6His-myc6His capacity to detect specifically the GTP-bound conformation of several recombinant RHO proteins was assessed in a direct ELISA assay. We confirm with ten-fold serial dilutions of the RH12, from $1 \mu \mathrm{M}$ to $1 \mathrm{nM}$, that the nanobody in its reduced state was able to detect the CA mutant RHOA L63 but not the dominant negative (DN) RHOA N19, expressed with a N-terminal twin Strep-Tag® and HA tag (2SHARHO), and then captured on Strep-Tactin ${ }^{\circledR}$ plates. As expected, the CA mutants of RHOA homologues, RHOB L63 and RHOC L63 were similarly detected. Regarding RHOA family close homologs, no signal was obtained below $10 \mathrm{nM}$ for RAC1 L61, suggesting that RH12 is more selective towards RHOA-like than RAC1 active GTPases, and no signal was detected on the close homologue CDC42 (data not shown). RH12 showed full selectivity recognition towards the GTP-bound RHOA recombinant protein. Altogether these results demonstrated that the RH12 may be used as a non-natural RHO-GTP Binding Domain suitable for a capture-ELISA process. 


\section{Supplemental material}

DNA constructs. pAOT7-2SHA-RHO expression plasmids correspond to a pET bacterial expression vector backbone which allow inducible expression of amino-terminal tags $2 \mathrm{x}$-Strep-tag ${ }^{\circledR}$ (similar to Twin-Strep-tag ${ }^{\circledR}$ from IBA-Lifesciences $\left.{ }^{\circledR}\right)$ followed by HA tag (2SHA) in fusion with a RHO GTPase protein sequence deleted off the prenylation CAAX carboxy terminal motif. Cloning of RHOA WT, CA or DN mutants as well as RAC1 CA or CDC42 CA were previously described in ${ }^{1}$. RAC2 and RAC3 sequences were gene synthesized (GeneCust) and inserted into the pAOT7-2SHA vector using Acc65I and BamHI restriction enzymes.

Nanobodies expressed as Hs2dAb-6His-myc-6His resulted from the subcloning of Hs2dAb-6His myc, digested from pIB-GFP ${ }^{1}$ and inserted in a modified pHEN6-VHH-6His previously described in ${ }^{2}$, thus creating a periplasmic expression vector pHEN6-Hs2dAb-6His-myc-6His. The Hs2dAb-6His-myc6 His were further subcloned NcoI-EcoRI into the pAOT7-VHHCATHA ${ }^{1}$ bacterial expression vector for cytoplasmic proteins, thus leading to the pAOT7-Hs2dAb-6His-myc-6His.

2SHA-RHO protein expression and purification: 2SHA-RHO were expressed in BL21(DE3) E.coli cells from a pET vector as previously described ${ }^{1}$. Transformed bacteria cells were used to grow $3 \mathrm{~mL}$ LB-carbenicillin $(100 \mu \mathrm{g} / \mathrm{ml})$ cultures overnight at $37^{\circ} \mathrm{C}$ prior to inoculation in baffled flasks containing $1 \mathrm{~L}$ of the same media. Cells were allowed to grow at $37^{\circ} \mathrm{C}$ until OD600 reached 0.5-0.7. Cells were then induced with IPTG at a final concentration of $100 \mu \mathrm{M}$ and grown for an additional 20 hours at $25^{\circ} \mathrm{C}$. Cells were harvested by centrifugation at $4000 \mathrm{~g}$ for $20 \mathrm{~min}$. The pellets were re-suspended in lysis buffer (50 mM TrisHCl pH 8, $150 \mathrm{mM} \mathrm{NaCl}, 5 \mathrm{mM} \mathrm{MgCl} 2,0.1 \%$ triton, 1mM DTT, 1 X lysozyme and DNase I, protease inhibitors) and lyzed by sonication on ice prior to centrifugation (30 min, 15000g, $\left.4^{\circ} \mathrm{C}\right)$. Strep-Tactin SuperFlow Plus (IBA $\left.{ }^{\circledR}\right)$ matrix was equilibrated in buffer A (50 mM TrisHCl pH 8.0, $150 \mathrm{mM} \mathrm{NaCl}, 5 \mathrm{mM} \mathrm{MgCl} 2$ ) and was incubated with supernatant for 2 hours at $4^{\circ} \mathrm{C}$. Then supernatant and matrix were loaded on a simple column in order to maximize capture of 2SHA-RHO proteins. Matrix was washed by $15 \mathrm{~mL}$ of washing buffer $(50 \mathrm{mM}$ Tris $\mathrm{HCl} \mathrm{pH} 8.0,300 \mathrm{mM}$ Nacl, 5 $\mathrm{mM} \mathrm{MgCl} 2,0.1 \%$ tween20). RHO proteins were then eluted in buffer A containing $10 \mathrm{mM}$ Biotin (Sigma). Dialysis was proceeded overnight against buffer A containing 15\% glycerol.

Affinity measurement. Hs2dAb binding studies based on SPR technology were performed on BIAcore T200 optical biosensor instrument (GE Healthcare ${ }^{\circledR}$ ). Capture of recombinant Hs2dAb-6His-myc-6His, expressed in XL1blue and purified as previously reported ${ }^{2}$, was performed on a nitrilotriacetic acid (NTA) sensor chip in HBS-P+ buffer (10 mM Hepes pH 7.4, $150 \mathrm{mM} \mathrm{NaCl}$, and $0.05 \%$ surfactant P20) (GE Healthcare). The four flow cells (Fc) of the sensor chip were used: one ( $\mathrm{Fc} 1)$ to monitor nonspecific binding and to provide background corrections for analyses and the other three flow cells ( $\mathrm{Fc} 2,3$, and 4) containing immobilized Hs2dAb-6His for measurement. 
For immobilization strategies, flow cells were loaded with nickel solution $(10 \mu \mathrm{L} / \mathrm{min}$ for $60 \mathrm{~s})$ in order to saturate the NTA surface with Ni2+ and an extra wash using running buffer containing $3 \mathrm{mM}$ EDTA after the nickel injection. His-tagged $\mathrm{Hs} 2 \mathrm{dAb}$ in running buffer was injected in flow cells at a flow-rate of $10 \mu \mathrm{L} / \mathrm{min}$. Total amount of immobilized Hs2dAb-6His was 250-300 resonance units. (RUs; 1 RU corresponds approximately to $1 \mathrm{pg} / \mathrm{mm}^{2}$ of protein on the sensor chip). A Single-Cycle Kinetics (SCK) analysis to determine association, dissociation and affinity constants (ka, kd, and KD respectively) was carried out. SCK method prevents potential inaccuracy due to sensor chip regeneration between cycles which are necessary in the conventional multiple cycle kinetics (MCK $)^{3}$. SCK binding parameters are evaluated for each injection according to the tools and fit models of the BIAevaluation software, giving similar values than MCK. Hs2dAb were captured on the sensor chip then the recombinant antigens were used as analyte and were injected sequentially with increased concentrations ranging between $3.125 \mathrm{nM}$ to $50 \mathrm{nM}$ in a single cycle without regeneration of the sensor chip between injections. Binding parameters were obtained by fitting the overlaid sensorgrams with the 1:1 Langmuir binding model of the BIAevaluation software version 1.0.

siRNA treatment. HeLa / HeLa S3 cells were transfected with either a siRNA control (siGENOME Non targeting siRNA pool \#1 D-001206-13-20 (Dharmacon)) or a siRNA targeting RHOA (siGENOME Human RHOA (387) siRNA-SMARTpool M-003860-03-0005 (Dharmacon)), RHOB (siGENOME Human RHOB (388) siRNA-SMARTpool M-008395-04-0005 (Dharmacon)), RHOC (siGENOME Human RHOC (389) siRNA-SMARTpool M-008555-01-0005 (Dharmacon)) or RAC1 (s11711 (Ambion)). 2 days after transfection, cells were recovered in order to perform the RH12 ELISA on 50 $\mu \mathrm{g}$ total protein input by well for RHOA, RHOC and RAC1 and on $125 \mu \mathrm{g}$ total protein input by well for RHOB and the immunoblotting on $50 \mu \mathrm{g}$ total protein input by well.

G-LISA assays. Levels of activated RHOA, RHOB and RHOC were determined using the G-LISA ${ }^{\circledR}$ RHOA Activation Assay Biochem Kit ${ }^{\mathrm{TM}}$ (\#BK124, Cytoskeleton $\left.{ }^{\circledR}\right)$. The G-LISA ${ }^{\circledR}$ kit was performed according to the manufacturer's instructions with the exception that RHOB (C-5, sc-8048, Santa Cruz Biotechnology, Inc.) and RHOC (37, sc-130339, Santa Cruz Biotechnology, Inc.) specific antibodies were used to detect the amount of captured active RHOB and RHOC respectively ${ }^{4}$. Levels of activated RAC1 were determined using the G-LISA ${ }^{\circledR}$ RAC1 Activation Assay BiochemKit ${ }^{\mathrm{TM}}$ (\#BK128, Cytoskeleton $\left.{ }^{\circledR}\right)$.

(1) Moutel, S.; Bery, N.; Bernard, V.; Keller, L.; Lemesre, E.; de Marco, A.; Ligat, L.; Rain, J.-C.; Favre, G.; Olichon, A.; Perez, F. NaLi-H1: A Universal Synthetic Library of Humanized Nanobodies Providing Highly Functional Antibodies and Intrabodies. eLife 2016, 5. https://doi.org/10.7554/eLife.16228.

(2) Olichon, A.; Surrey, T. Selection of Genetically Encoded Fluorescent Single Domain Antibodies Engineered for Efficient Expression in Escherichia Coli. J. Biol. Chem. 2007, 282 (50), 36314-36320. https://doi.org/10.1074/jbc.M704908200.

(3) Trutnau, H.-H. New Multi-Step Kinetics Using Common Affinity Biosensors Saves Time and Sample at Full Access to Kinetics and Concentration. J. Biotechnol. 2006, 124 (1), 191-195. https://doi.org/10.1016/j.jbiotec.2006.01.006.

(4) Howe, G. A.; Addison, C. L. RhoB Controls Endothelial Cell Morphogenesis in Part via Negative Regulation of RhoA. Vasc. Cell 2012, 4 (1), 1. https://doi.org/10.1186/2045-824X-4-1. 


\section{Supplemental Table legends.}

\section{Supplemental Table 1: RH12 nanobody affinity determination by SPR.}

Summary table of all KD values obtained by Single-Cycle kinetics (SCK) for the RH12-6His-myc-6His nanobody immobilized on NTA sensor chip (250-300 RU), with five injections of purified 2SHA-RHO variants as analytes injected at $3.125 \mathrm{nM}, 6.25 \mathrm{nM}, 12.5 \mathrm{nM}, 25 \mathrm{nM}$ and $50 \mathrm{nM}$ (RHOA constitutively active mutant L63, RHOB L63, RHOC L63, RAC1 L61 or CDC42 L61, RHOA constitutively inactive mutant N19 and RHOA WT loaded with either GTP $\gamma$ S or GDP). SCK analysis was done by the BIAevaluation software.

Supplemental Table 2: Histo-pathological characteristics of tumor samples included in our cohort. Age of patients, tumor size $(\mathrm{T})$, lymph node involvement $(\mathrm{N})$ and pathological grade of the tumor samples are presented according to the four main cancer subtypes defined by the expression of hormonal and HER2 receptors, i.e., TNBC, HR-HER2+, HR+HER2+, HR+HER2-.

Supplemental Table 3: RHO protein expression and active state levels among the different breast cancer subtypes. P values were calculated using a Kruskal-Wallis test for RHO expression and RHO-GTP activities. 


\section{Supplemental Figure legends.}

Supplemental Figure 1: G-LISA commercial assay detection of endogenous RHOA, RHOB, RHOC and RAC1 active conformations.

Absorbance at $485 \mathrm{~nm}$ reflects dose-effect of HeLa or HeLa S3 cell extract loaded with GTP $\gamma \mathrm{S}$ or GDP for (A) RHOA (B) RHOB (C) RHOC and (D) RAC1. P values were calculated using a Two-Way ANOVA. ** $\mathrm{p}<0.01, * * * \mathrm{p}<0.001, * * * * \mathrm{p}<0.0001$

Supplemental Figure 2: RH12 selective capture of CA 2SHA-RHOA, RHOB, RHOC and RAC1 recombinant proteins.

Nickel-coated plates were coated with either RH12 or NR53 Hs2dAb-6His-myc-6His at $0.5 \mu \mathrm{M}$ and absorbance at $450 \mathrm{~nm}$ reflects HRP-conjugated Strep-Tactin signal. (A) Scheme of the capture-ELISA assay. Various recombinant $2 \mathrm{SHA}-\mathrm{RHO}$ purified proteins were assayed at concentration ranging from 0.1 to $100 \mathrm{nM}$. (B) 2SHA-RHOA L63, (C) 2SHA-RHOA N19, (D) 2SHA-RHOB L63, (E) 2SHARHOC L63, (F) 2SHA-CDC42 L61, (G) 2SHA-RAC1 L61 (H) 2SHA-RAC2 L61 or (I) 2SHA-RAC3 L61.

Supplemental Figure 3: RHO / RAC GTP active state determination with RH12 ELISA and total RHO / RAC expression after siRNA treatment

HeLa (for RHOA and RHOC) or HeLa S3 (for RHOB and RAC1) cells were transfected with either a siRNA control or a siRNA targeting RHOA, RHOB, RHOC or RAC1. Extinction of RHO protein expression by siRNA validates RH12 specific capture of RHO proteins in the complexity of cellular extracts. P values were calculated using a Student's t-test. $* * \mathrm{p}<0.01, * * * \mathrm{p}<0.001, * * * * \mathrm{p}<0.0001$

Supplemental Figure 4: RH12 capture ELISA of endogenous RHOA active conformation. Nickel-coated plate was coated with RH12 Hs2dAb at $0.5 \mu \mathrm{M}$ and absorbance at $450 \mathrm{~nm}$ reflects doseeffect of HeLa cell extract loaded with GTP $\gamma \mathrm{S}$ or GDP. P value was calculated using a Student's t-test. $* * * * \mathrm{p}<0.0001$

Supplemental Figure 5: Flow chart of patient breast normal and tumor tissue analysis of RHOA and RHOC active state and expression.

This flow chart depicts how tumor samples and their normal counterparts were used through our study. RHOA and RHOC expression was not detectable by Western-Blot in some samples, which is the reason why only 63 samples were finally assessed for RHOA and 58 for RHOC.

Supplemental Figure 6: RHO / RAC GTP active state determination with RH12 ELISA on breast tumor tissues and their normal counterparts

Nickel-coated plates were coated with RH12 Hs2dAb at $0.5 \mu \mathrm{M}$ and GTP active state was determined for (A) RHOA on $100 \mu \mathrm{g}$ (B) RHOB on $150 \mu \mathrm{g}$ (C) RHOC on $50 \mu \mathrm{g}$ (D) RAC1 on $100 \mu \mathrm{g}$ total protein input by well for tumors versus their matched normal tissues $(n=15)$. The Wilcoxon signed-rank test was used to compare matched samples. The difference in RHOA and RHOC GTP active state between tumors and their normal counterparts is significant with $\mathrm{p}=0.0054 * *$ and $\mathrm{p}=0.0007 * * *$ respectively. There is no significant difference for RHOB and RAC1 GTP active state between tumors and normal tissues. 


\section{Supplemental Figure 7: RHOA and RHOC expression on breast tumor tissues compared to their}

normal adjacent counterparts.

(A) RHO total expression quantified by western blot on $30 \mu \mathrm{g}$ input of breast tumors and their normal adjacent tissues and normalized with total protein staining. The Wilcoxon signed-rank test was used to compare matched samples. The difference in total RHOC expression between tumors and their normal counterparts is significant with $\mathrm{p}=0.0012^{* *}$ (B) Spearman correlation of GTP-bound RHOA (left) and RHOC (right) with total RHOA and RHOC expression levels in tumor tissues. (C) Spearman correlation of GTP-bound RHOA (left) and RHOC (right) with total RHOA and RHOC expression levels in normal counterparts.

\section{Supplemental Figure 8: RHOA and RHOC expression is independent from their active state levels} in breast tumor subtypes.

(A) Total RHOA (left) and RHOC (right) expression levels across breast cancer subtypes. The MannWhitney test was used for pairwise comparisons and $\mathrm{P}$ values were adjusted with Benjamini-Hochberg procedure. ${ }^{*} \mathrm{p}<0.05$ (B) Spearman correlations between RHOA expression quantified by western blot, normalized with total protein staining, and GTP-bound RHOA active state in RH12-based ELISA in the 4 breast cancer subtypes. (C) Spearman correlations between RHOC expression quantified by western blot, normalized with total protein staining, and GTP-bound RHOC active state in RH12-based ELISA in the 4 breast cancer subtypes. 
Supplemental Table 1:

\begin{tabular}{|c|c|c|c|c|}
\hline RHO & RU & $\mathrm{Ka}\left(\mathrm{M}^{-1} \cdot \mathrm{s}^{-1}\right)$ & $\mathrm{Kd}\left(\mathrm{s}^{-1}\right)$ & KD (M) \\
\hline RHOA L63 & 900 & $7.42 \times 10^{+5}$ & $4.97 \times 10^{-4}$ & $0.7 \times 10^{-9}$ \\
\hline RHOB L63 & 900 & $3.06 \times 10^{+6}$ & $3943 \times 10^{-2}$ & $1.57 \times 10^{-9}$ \\
\hline RHOC L63 & 800 & $4.4 \times 10^{+7}$ & $1.03 \times 10^{-3}$ & $0.02 \times 10^{-9}$ \\
\hline RAC1 L61 & 1600 & $3.5 \times 10^{+10}$ & 183 & $5.22 \times 10^{-9}$ \\
\hline CDC42 L61 & no & & & ND \\
\hline RHOA N19 & no & & & ND \\
\hline $\begin{array}{c}\text { RHOA WT } \\
\text { GTP } \gamma \mathrm{S}\end{array}$ & 400 & $3.78 \times 10^{+5}$ & $4.67 \times 10^{-4}$ & $1.235 \times 10^{-9}$ \\
\hline $\begin{array}{c}\text { RHOA WT } \\
\text { GDP }\end{array}$ & 20 & $6.22 \times 10^{+4}$ & $9.719 \times 10^{-4}$ & $1.56 \times 10^{-8}$ \\
\hline
\end{tabular}


Supplemental Table 2:

\begin{tabular}{|c|c|c|c|c|c|}
\hline & TNBC & HR- HER2+ & HR+ HER2+ & HR+ HER2- & $p$ \\
\hline & $N=13$ & $N=15$ & $N=15$ & $N=21$ & \\
\hline Age ( $N=64)$ & & & & & 0.3927 \\
\hline $\begin{array}{l}\text { Median } \\
\text { (Range) }\end{array}$ & $\begin{array}{c}54 \\
(36-85)\end{array}$ & $\begin{array}{c}64 \\
(33-85)\end{array}$ & $\begin{array}{c}57 \\
(37-71)\end{array}$ & $\begin{array}{c}63 \\
(42-87)\end{array}$ & \\
\hline pT $(N=60)$ & & & & & 0.1219 \\
\hline I & $6(54.5 \%)$ & $4(26.7 \%)$ & $3(23.1 \%)$ & $6(28.6 \%)$ & \\
\hline ॥ & 5 (45.5\%) & 8 (53.3\%) & $10(76.9 \%)$ & 9 (42.9\%) & \\
\hline III/IV & $0(0.0 \%)$ & $3(20.0 \%)$ & $0(0.0 \%)$ & $6(28.6 \%)$ & \\
\hline Missing & 2 & 0 & 2 & 0 & \\
\hline $\mathrm{pN}(\mathrm{N}=59)$ & & & & & 0.2455 \\
\hline 0 & $8(72.7 \%)$ & $4(26.7 \%)$ & $5(38.5 \%)$ & $6(30.0 \%)$ & \\
\hline I & 1 (9.1\%) & 8 (53.3\%) & 5 (38.5\%) & $8(40.0 \%)$ & \\
\hline II/III & 2 (18.2\%) & $3(20.0 \%)$ & $3(23.1 \%)$ & $6(30.0 \%)$ & \\
\hline Missing & 2 & 0 & 2 & 1 & \\
\hline Grade $(N=64)$ & & & & & 0.0018 \\
\hline I & $3(23.1 \%)$ & $2(13.3 \%)$ & $8(53.3 \%)$ & 15 (71.4\%) & \\
\hline II/III & 10 (76.9\%) & $13(86.7 \%)$ & 7 (46.7\%) & $6(28.6 \%)$ & \\
\hline
\end{tabular}


Supplemental Table 3:

\begin{tabular}{|c|c|c|c|c|c|}
\hline & TNBC & HR- HER2+ & HR+ HER2+ & HR+ HER2- & $p$ \\
\hline & $N=13$ & $N=15$ & $N=15$ & $N=21$ & \\
\hline $\begin{array}{c}\text { RHOA } \\
\text { expression } \\
(N=63)\end{array}$ & & & & & 0.0831 \\
\hline $\begin{array}{c}\text { Median } \\
\text { (range) }\end{array}$ & $\begin{array}{c}0.3 \\
(0.0-2.3) \\
\end{array}$ & $\begin{array}{c}0.3 \\
(0.0-2.5) \\
\end{array}$ & $\begin{array}{c}0.4 \\
(0.1-3.4) \\
\end{array}$ & $\begin{array}{c}0.2 \\
(0.0-0.8) \\
\end{array}$ & \\
\hline Missing & 1 & 0 & 0 & 0 & \\
\hline $\begin{array}{c}\text { RHOC } \\
\text { expression } \\
(N=58)\end{array}$ & & & & & 0.0135 \\
\hline $\begin{array}{l}\text { Median } \\
\text { (range) }\end{array}$ & $\begin{array}{c}0.4 \\
(0.0-4.5)\end{array}$ & $\begin{array}{c}0.7 \\
(0.2-4.0)\end{array}$ & $\begin{array}{c}1.9 \\
(0.1-7.1)\end{array}$ & $\begin{array}{c}0.3 \\
(0.0-4.5)\end{array}$ & \\
\hline Missing & 3 & 0 & 2 & 1 & \\
\hline $\begin{array}{l}\text { RHOA-GTP } \\
\text { active state } \\
(\mathrm{N}=63)\end{array}$ & & & & & 0.0054 \\
\hline $\begin{array}{c}\text { Median } \\
\text { (range) }\end{array}$ & $\begin{array}{c}0.3 \\
(0.2-0.5) \\
\end{array}$ & $\begin{array}{c}0.3 \\
(0.2-0.5) \\
\end{array}$ & $\begin{array}{c}0.2 \\
(0.2-1.4) \\
\end{array}$ & $\begin{array}{c}0.4 \\
(0.3-1.1)\end{array}$ & \\
\hline Missing & 1 & 0 & 0 & 0 & \\
\hline $\begin{array}{l}\text { RHOC-GTP } \\
\text { active state } \\
(\mathrm{N}=64)\end{array}$ & & & & & 0.1894 \\
\hline $\begin{array}{c}\text { Median } \\
\text { (range) }\end{array}$ & $\begin{array}{c}0.5 \\
(0.3-1.0) \\
\end{array}$ & $\begin{array}{c}0.4 \\
(0.2-1.0) \\
\end{array}$ & $\begin{array}{c}0.4 \\
(0.2-0.6) \\
\end{array}$ & $\begin{array}{c}0.5 \\
(0.3-1.6) \\
\end{array}$ & \\
\hline Missing & 0 & 0 & 0 & 0 & \\
\hline
\end{tabular}


A RHOA reference G-LISA

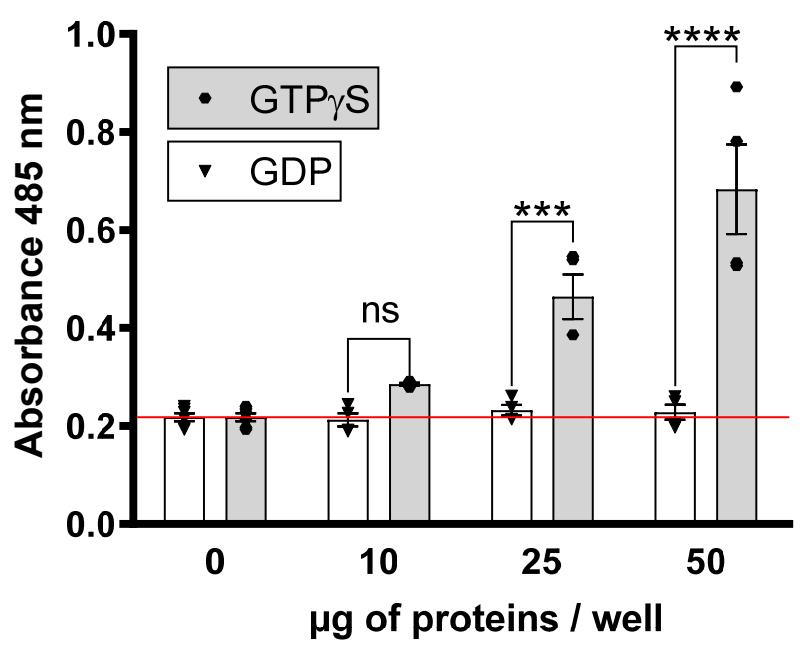

C RHOC reference G-LISA

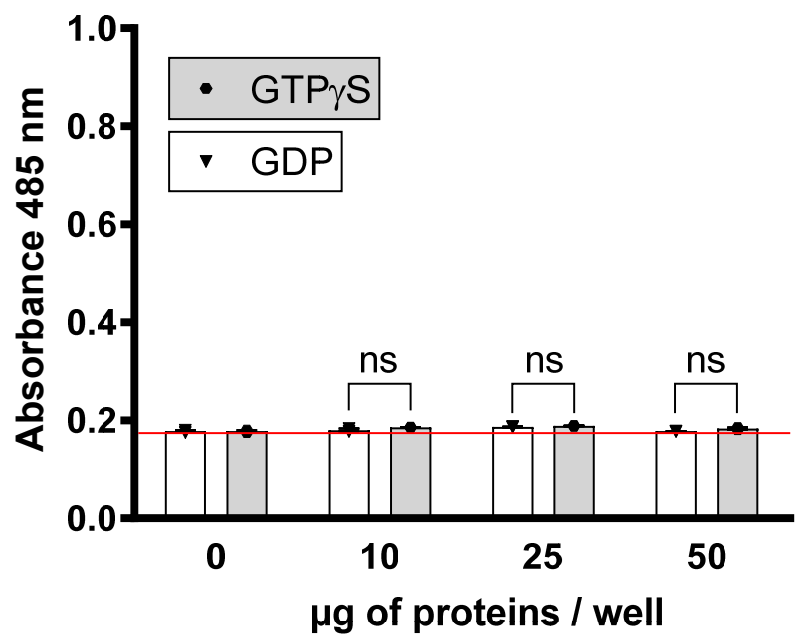

Supplemental Figure 1
B RHOB reference G-LISA

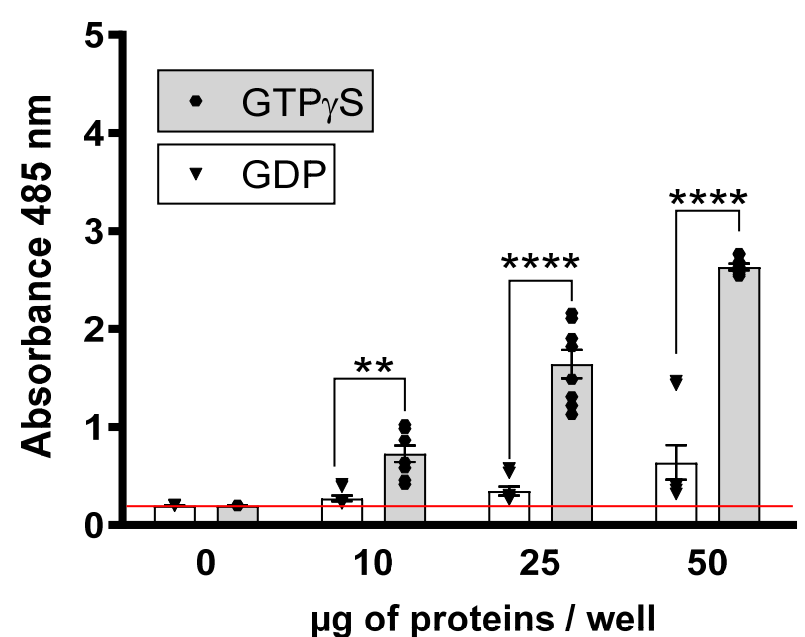

D RAC1 reference G-LISA

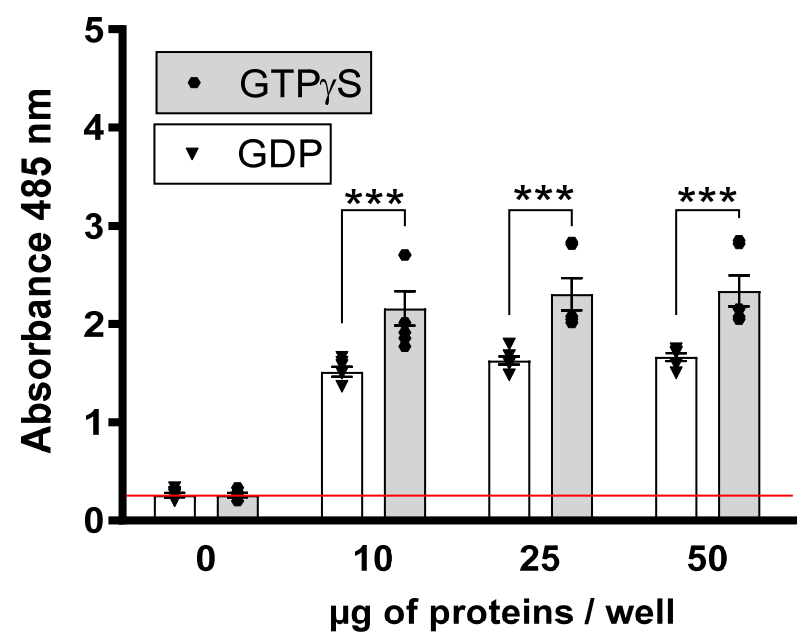


A

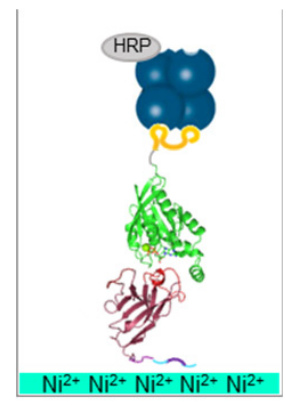

Strep-Tactin conjugated

\section{S-HA-RHO}

RH12-6His-Myc-6His

Nickel chelates coating

B

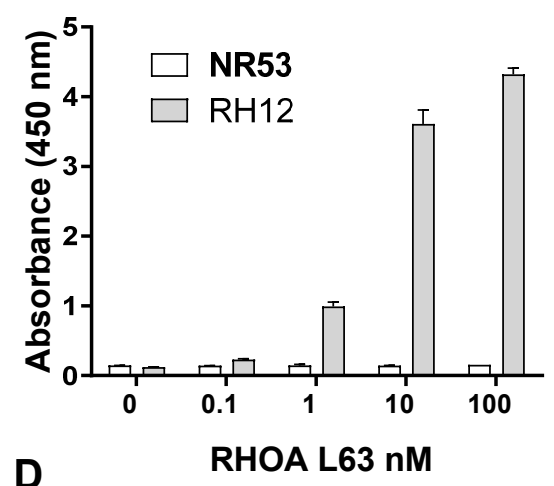

D

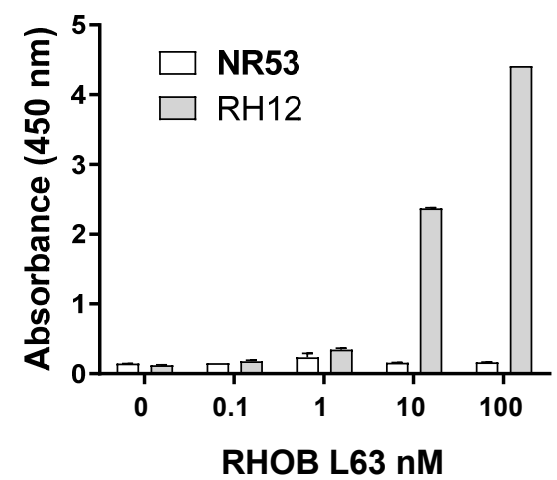

G

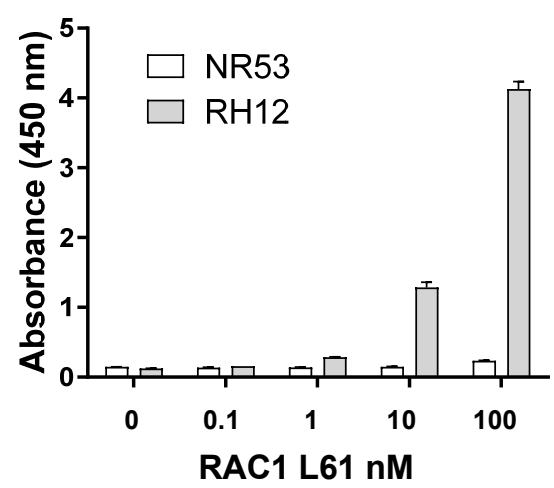

C

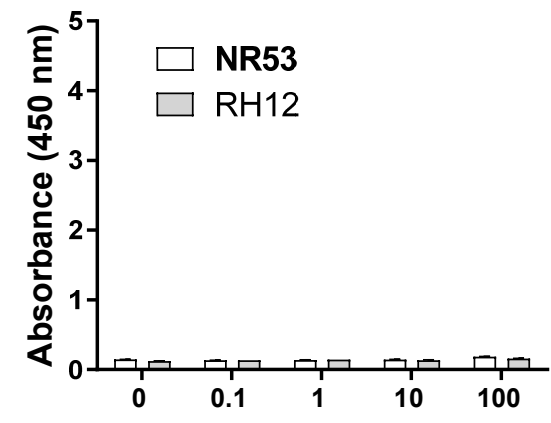

E

RHOA N19 nM

F

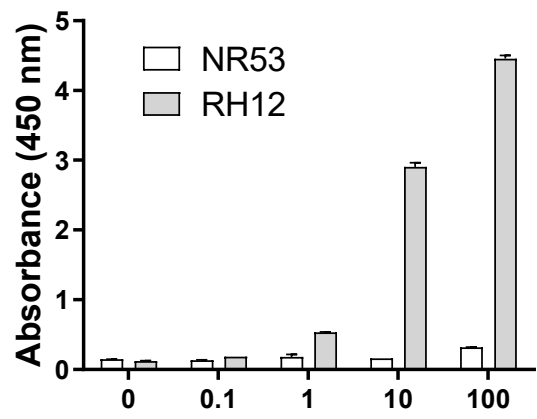

RHOC L63 nM

H

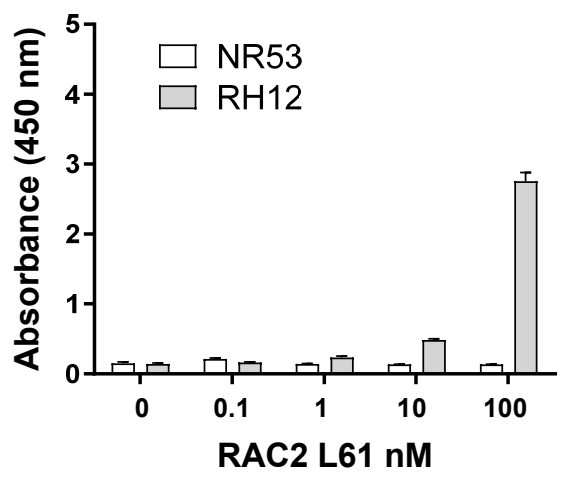

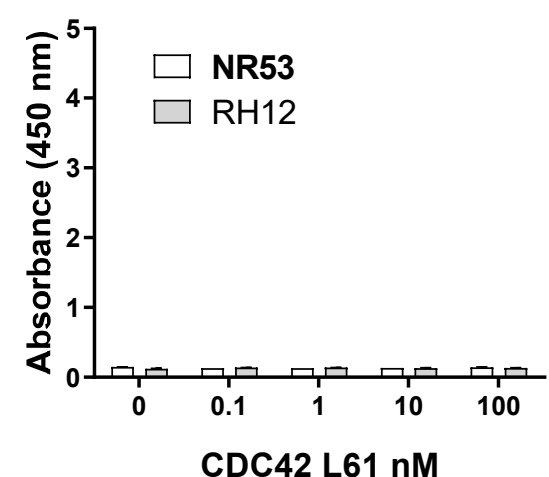

I

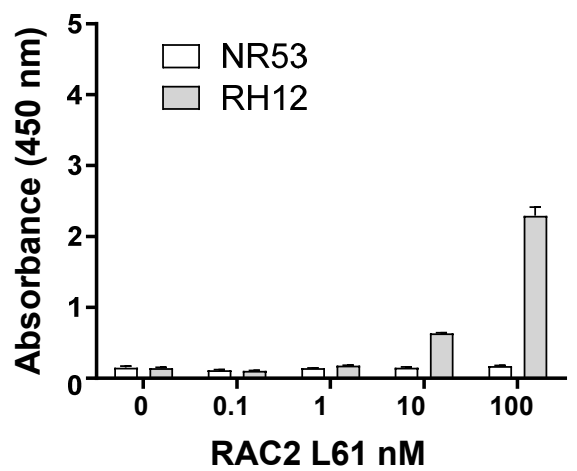

\section{Supplemental Figure 2}



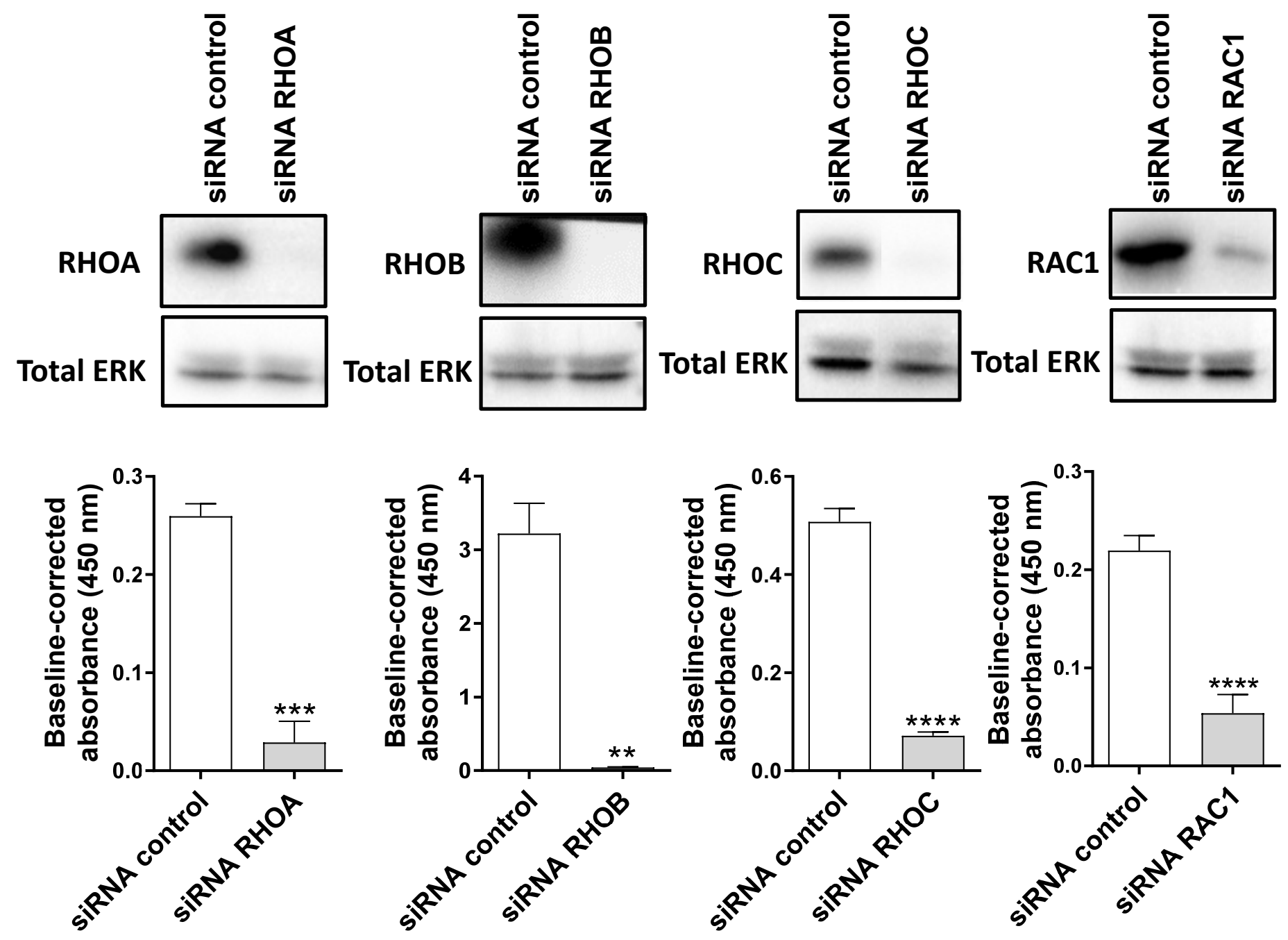

Supplemental Figure 3 


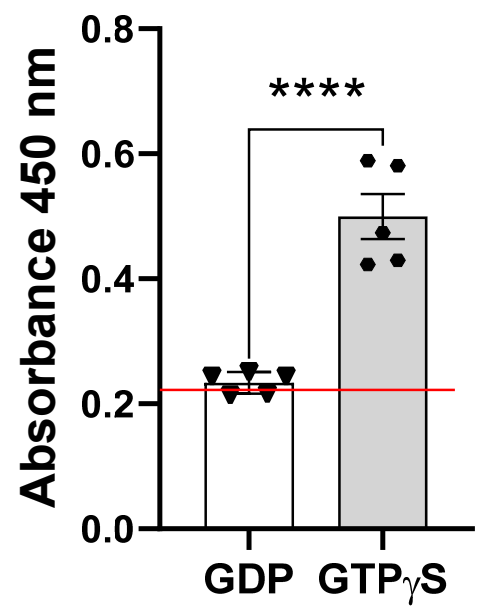

Supplemental Figure 4 


\begin{tabular}{|c|c|c|c|}
\hline TNBC & $\begin{array}{c}\text { HR- } \\
\text { HER2+ }\end{array}$ & $\begin{array}{c}\text { HR+ } \\
\text { HER2+ }\end{array}$ & $\begin{array}{c}\text { HR+ } \\
\text { HER2- }\end{array}$ \\
\hline 4 & 3 & 6 & 21 \\
\hline
\end{tabular}

Tumors + Normal tissues

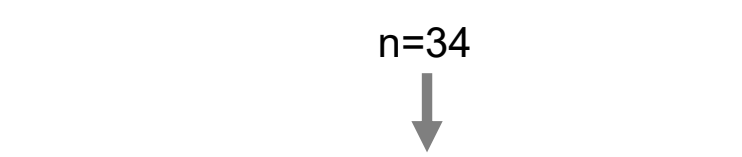

\begin{tabular}{|c|c|}
\hline RHOA & RHOC \\
\hline RHO-GTP Active state \\
\hline Total RHO expression / Total protein staining \\
\hline
\end{tabular}

\begin{tabular}{|c|c|c|c|}
\hline TNBC & $\begin{array}{c}\text { HR- } \\
\text { HER2+ }\end{array}$ & $\begin{array}{c}\text { HR+ } \\
\text { HER2+ }\end{array}$ & $\begin{array}{c}\text { HR+ } \\
\text { HER2- }\end{array}$ \\
\hline 9 & 12 & 9 & 0 \\
\hline
\end{tabular}

\section{Tumors}

(w/o Normal tissues)
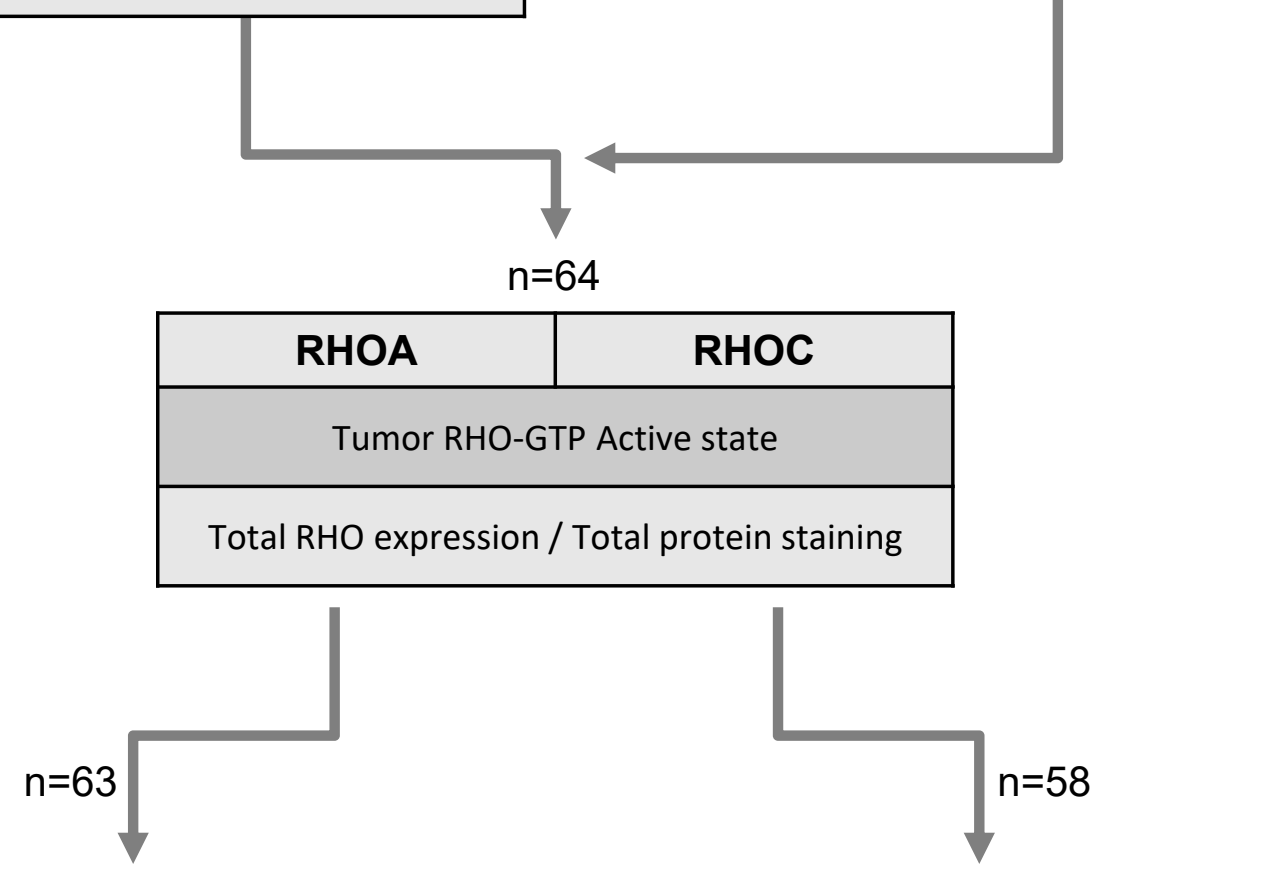

\begin{tabular}{|c|c|c|c|}
\hline \multicolumn{4}{|c|}{ RHOA } \\
\hline TNBC & $\begin{array}{c}\text { HR- } \\
\text { HER2+ }\end{array}$ & $\begin{array}{c}\text { HR+ } \\
\text { HER2+ }\end{array}$ & $\begin{array}{c}\text { HR+ } \\
\text { HER2- }\end{array}$ \\
\hline 12 & 15 & 15 & 21 \\
\hline
\end{tabular}

\begin{tabular}{|c|c|c|c|}
\hline \multicolumn{4}{|c|}{ RHOC } \\
\hline TNBC & $\begin{array}{c}\text { HR- } \\
\text { HER2+ }\end{array}$ & $\begin{array}{c}\text { HR+ } \\
\text { HER2+ }\end{array}$ & $\begin{array}{c}\text { HR+ } \\
\text { HER2- }\end{array}$ \\
\hline 10 & 15 & 13 & 20 \\
\hline
\end{tabular}

\section{Supplemental figure 5}


A

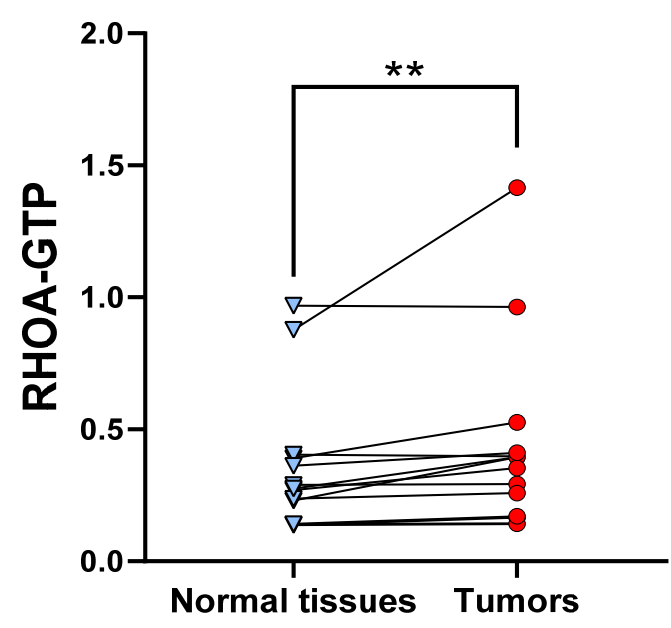

C

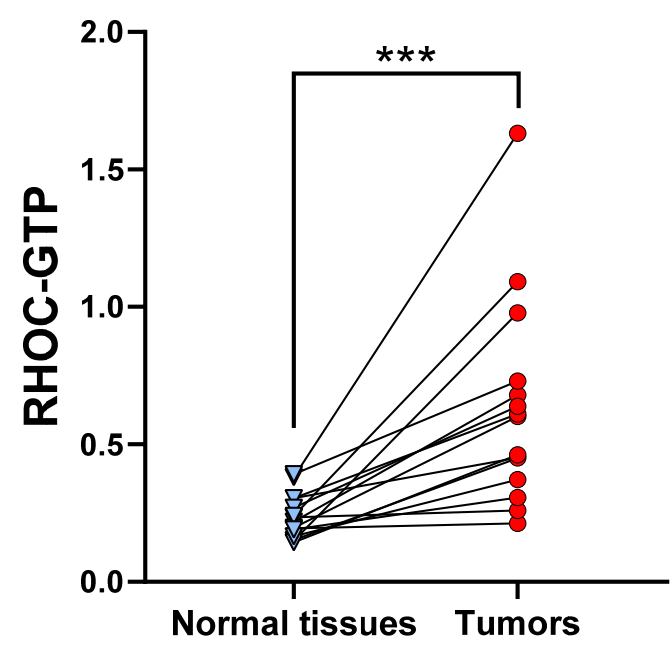

Supplemental figure 6

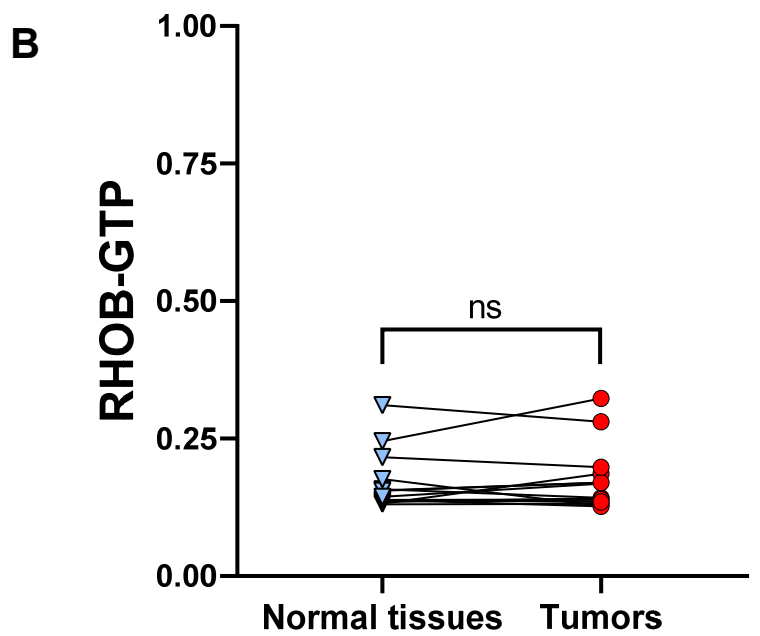

D

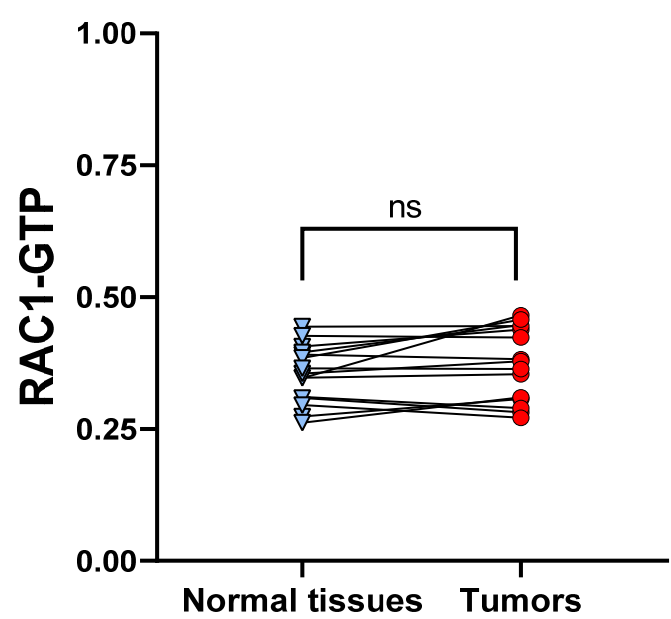


A

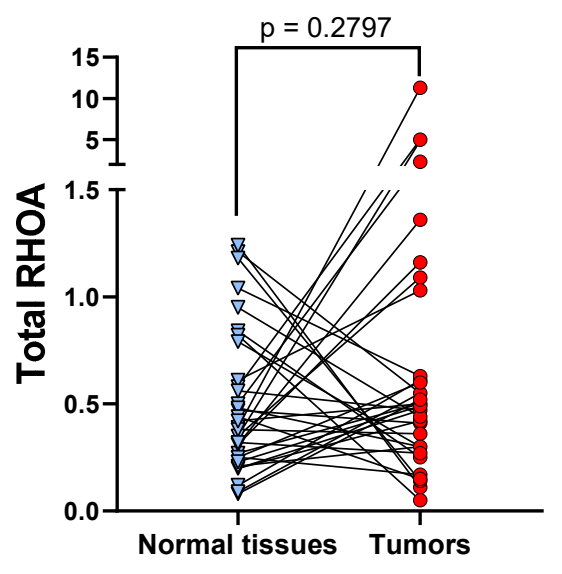

B

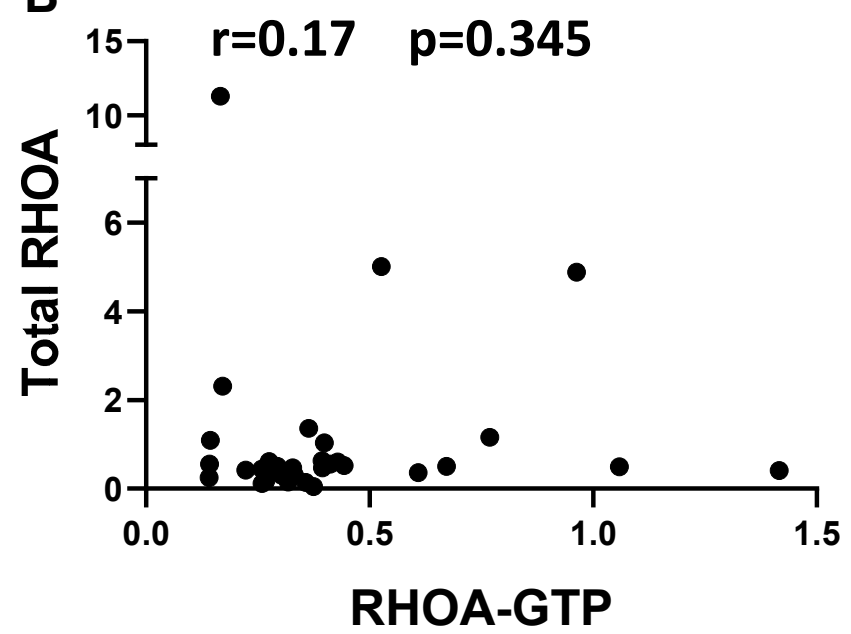

C

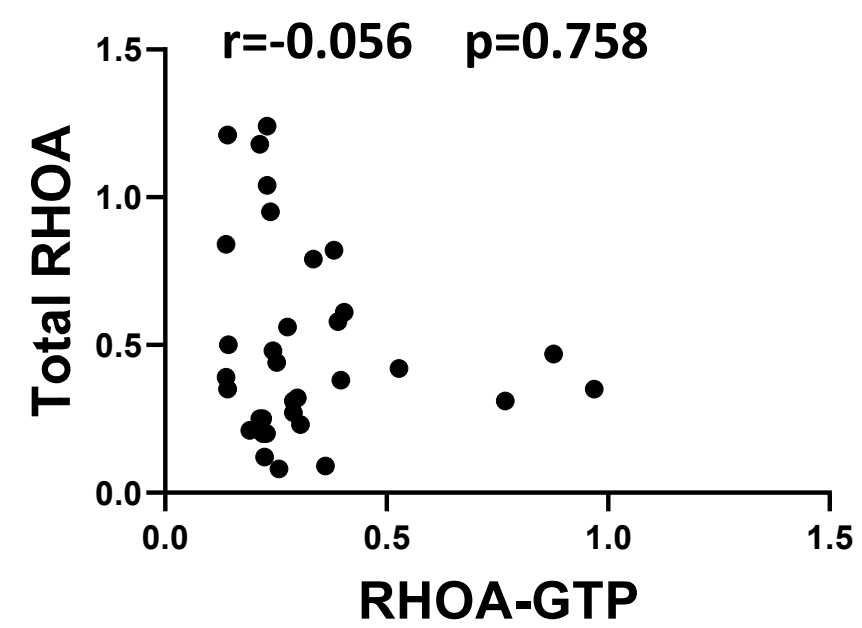

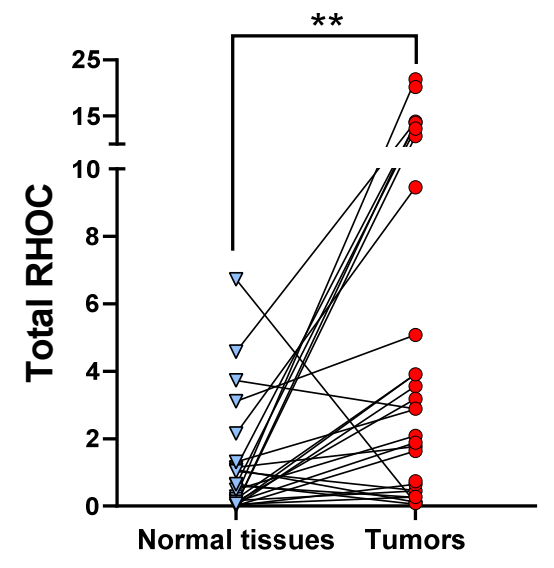
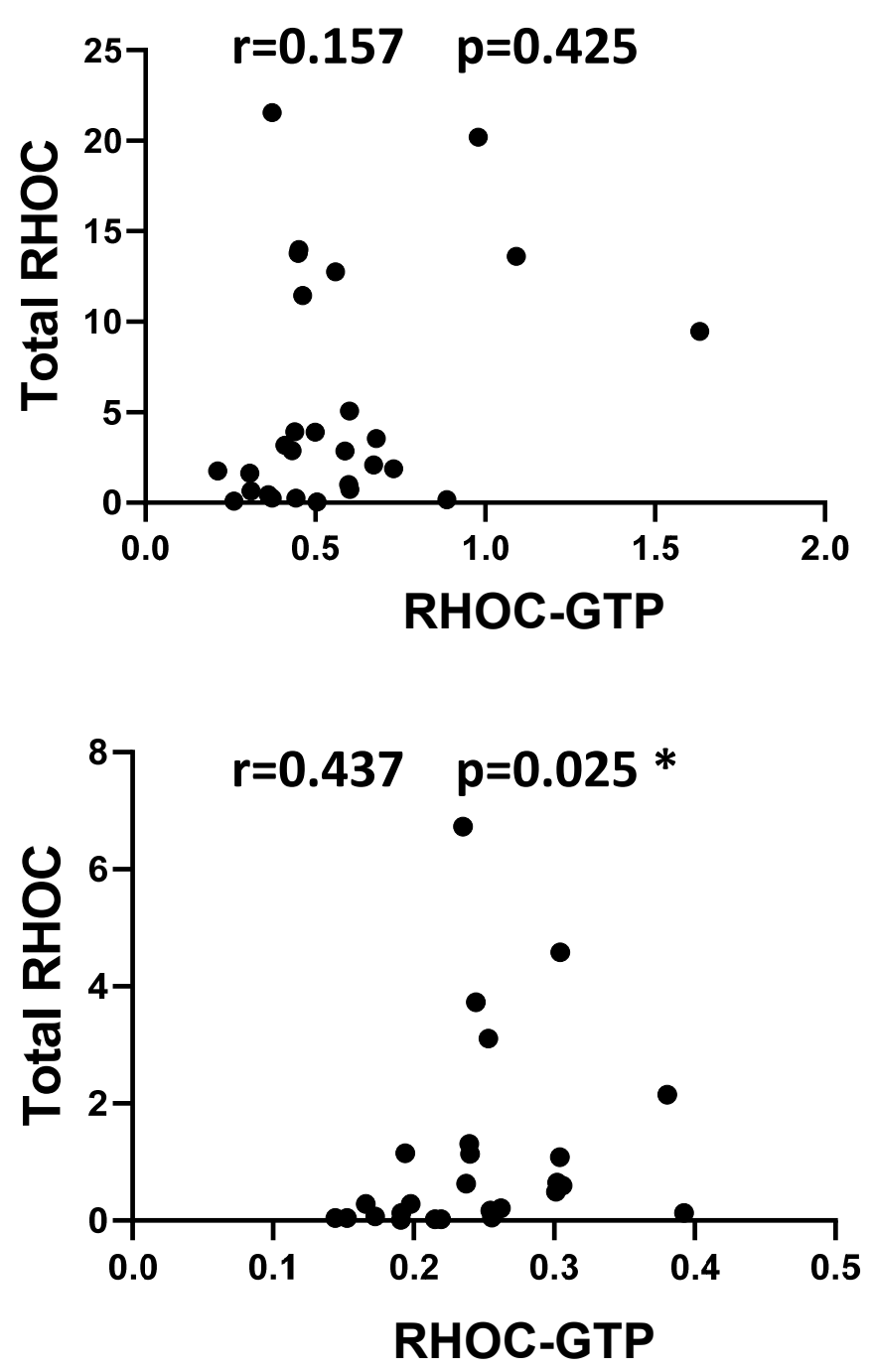

Supplemental Figure 7 
A

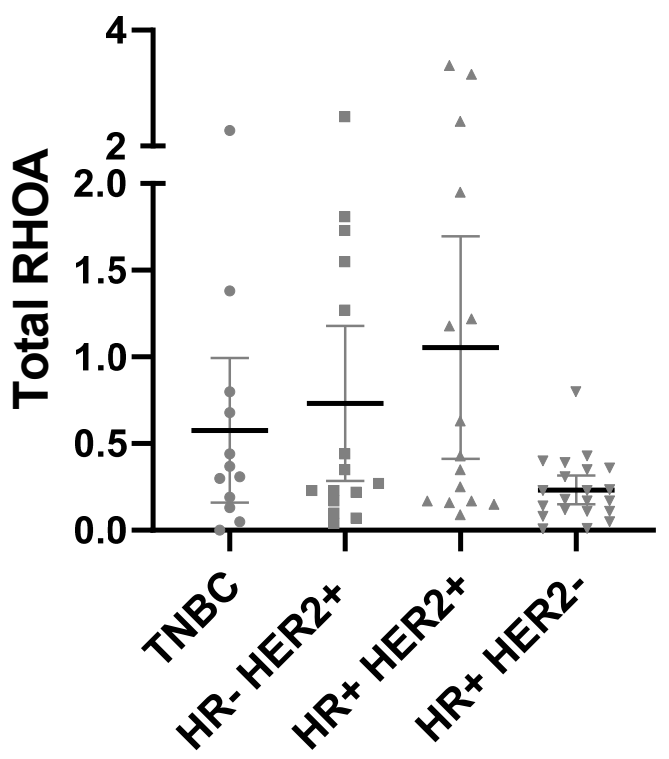

B

TNBC

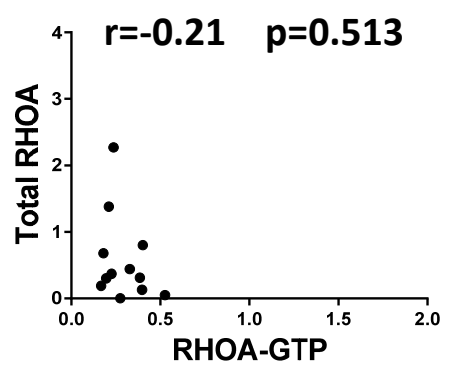

C TNBC
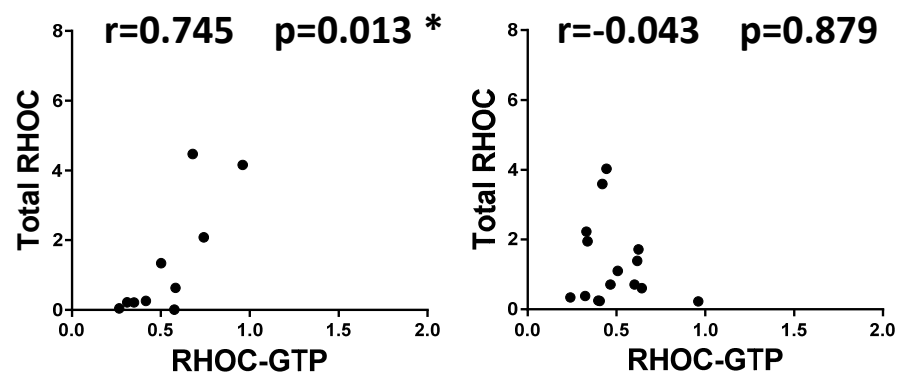

HR- HER2+

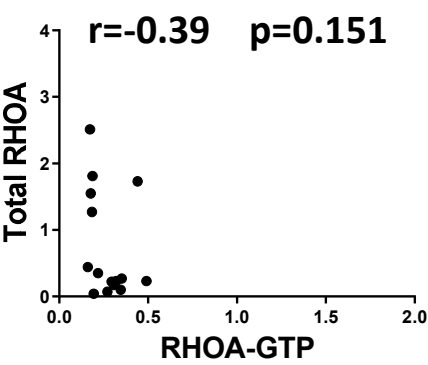

HR- HER2+

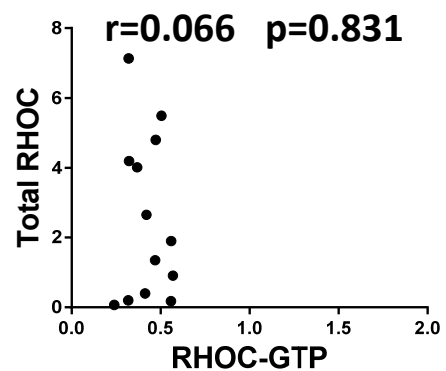

HR+ HER2+

HR+ HER2+
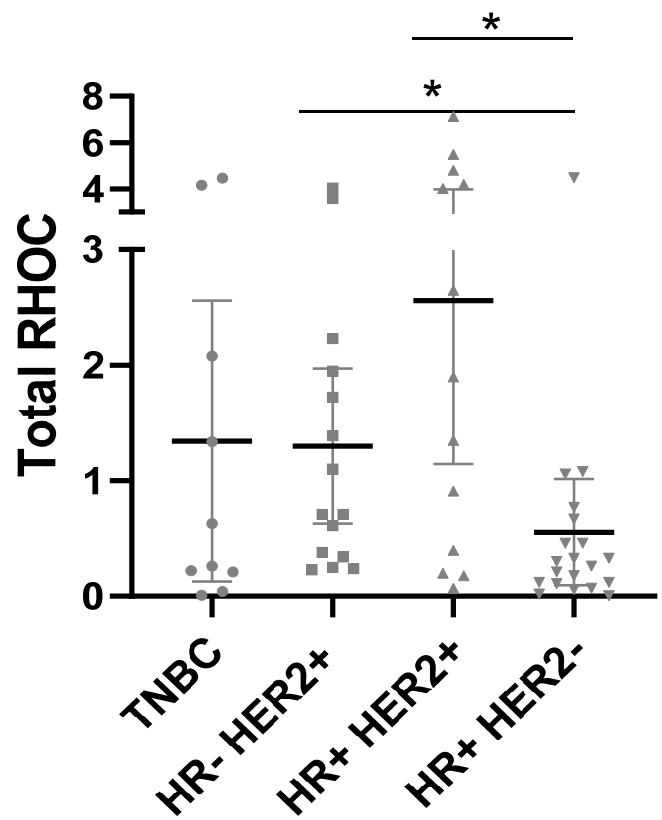

HR+ HER2-
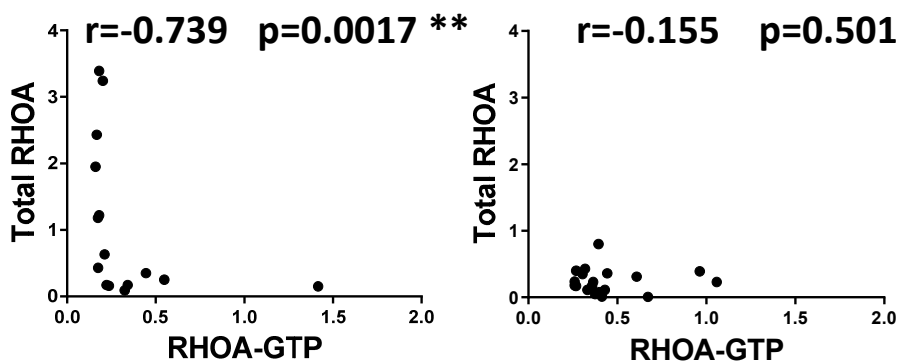

HR+ HER2-

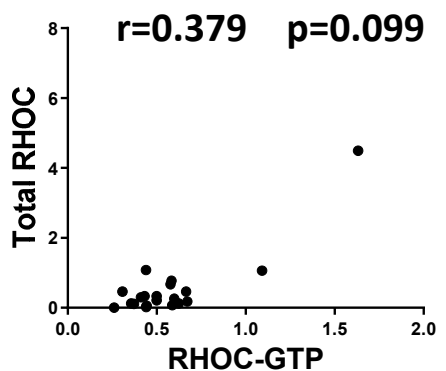

Supplemental Figure 8 